\title{
ESTUDIO GEOQUIMICO DE LOS SEDIMENTOS SUPERFICIALES DEL LITORAL NORORIENTAL DEL GOLFO DE CARIACO, ESTADO SUCRE, VENEZUELA
}

\author{
Arístide Márquez ${ }^{1}$ Jaime Bonilla ${ }^{1,}$ Gregorio Martínez ${ }^{1}$, William Senior ${ }^{1}$, \\ Damarys Aguilera² \& Ángel GonzÁlez ${ }^{3}$ \\ ${ }^{1}$ Instituto Oceanográfico de Venezuela, Universidad de Oriente, Cumaná, Venezuela. \\ aristide@sucre.udo.edu.ve \\ ${ }^{2}$ Universidad de Oriente, Escuela de Ciencias, Cumaná, Venezuela. \\ ${ }^{3}$ Instituto Limnológico. UDO. Núcleo Bolívar
}

\begin{abstract}
Resumen: Algunos aspectos geoquímicos de los sedimentos superficiales del litoral de la costa nororiental del Golfo de Cariaco, estado Sucre, Venezuela, son presentados en esta investigación. La estructura geológica del Golfo es tectónica con presencia de sistema de fallas, en donde los sedimentos del litoral norte pueden ser texturizados como arenosos por ser bastantes permeables en su mayoría y presentar un contenido hídrico promedio de $22,44 \%$. Los contenidos de materia orgánica determinados fueron bajos con promedios de 7,63\%, detectándose porcentajes de carbono orgánico de $0,97 \%$ y $21,97 \%$ de carbonatos de calcio. Se apreciaron concentraciones altas de fósforo $\left(360,03 \mu \mathrm{g} . \mathrm{g}^{-1}\right)$ y de nitrógeno total $(396,29$ $\mu \mathrm{g} . \mathrm{g}^{-1}$ ), siendo la relación entre estos elementos de 1,09, indicando cierto grado de fertilidad orgánica. Las concentraciones de metales presentaron distribuciones discrepantes, con promedios para hierro de 3348,58 $\mu \mathrm{g} . \mathrm{g}^{-1}$, manganeso $14,63 \mu \mathrm{g} \cdot \mathrm{g}^{-1}$, níquel $13,68 \mu \mathrm{g} \cdot \mathrm{g}^{-1}$, cinc $11,59 \mu \mathrm{g} \cdot \mathrm{g}^{-1}$, cromo $10,23 \mu \mathrm{g} \cdot \mathrm{g}^{-1}$, cobre $2,29 \mu \mathrm{g} \cdot \mathrm{g}^{-1}$, cadmio $1,04 \mu \mathrm{g} \cdot \mathrm{g}^{-1} \mathrm{y}$ plomo $0,57 \mu \mathrm{g} \cdot \mathrm{g}^{-1}$ mostrándose contaminación, especialmente por cadmio. La no linealidad presentada por algunos metales como plomo, cobre, níquel y manganeso con el hierro, sugiere la existencia de entradas de tipo no natural, causadas por fuentes de origen antropogénico. Esta fuente probablemente está influenciada por descargas fluviales, industriales y por el aporte exógeno unidireccional desde la costa sur.
\end{abstract}

Palabras claves. Golfo de Cariaco, estudio geoquímico, sedimentos.

Abstract: This research presents some geochemical aspects of the marine surface sediments of the north coast of the Gulf of Cariaco, in the state of Sucre, Venezuela. The gulf has a tectonic structure and a fault system mainly featuring sandy sediments, most of which are quite permeable and have an average hydric content of $22.44 \%$. The content of organic matter detected was low, averaging $7.63 \%$, organic carbon and calcium carbonate commanding $0.97 \%$ and $21.97 \%$, respectively. Contrarily, phosphorus and total nitrogen were high, $360.03 \mathrm{mg} \cdot \mathrm{g}^{-1}$ for the former and $396.29 \mathrm{mg} \cdot \mathrm{g}^{-1}$ for the latter, the total nitrogen to phosphorus ratio being 1.09 , which indicates a certain degree of organic fertility. The metal concentrations presented different distributions, averaging $3548.58,14.63,13.68,11.59,10.23,2.29,1.04$, and $0.57 \mathrm{mg} . \mathrm{g}^{-1}$ for iron, manganese, nickel, zinc, chromium, copper, cadmium, and lead, respectively, indicative of contamination, especially by cadmium. The nonlinearity with the iron presented by some metals such as copper, nickel, and manganese suggests the existence of anthropogenic influxes, probably swayed by river-borne industrial contributions, including the exogenous discharges running seawards from the south coast.

Key words: Gulf of Cariaco, geochemistry study, sediments.

\section{INTRODUCCIÓN}

Durante el Pleistoceno Inferior, ante los movimientos tectónicos ocurridos en las elevaciones de las montañas de Araya (Venezuela), ocurrieron hundimientos y elevaciones desiguales, dando origen a la cuenca de
Cariaco, separándose la cordillera Caribe del norte en Venezuela y produciéndose los sistemas Central y Oriental, que originaron una incipiente cuenca de sedimentación que conformó posteriormente el Golfo de Cariaco hace 
aproximadamente de 800.000 a 1.000 .000 de años A.P (CAraballo, 1982). El Golfo de Cariaco se encuentra dominado por rocas metamórficas de edad Mesozoica (Vignali, 1965; Bermúdez, 1966; Schubert, 1972), y por los afloramientos de rocas sedimentarias del Cenozoico Tardío y del Pleistoceno en el extremo occidental de la Península de Araya y en la parte sureste cerca de Campoma (Macsotay \& CARABAllo, 1976).

Las masas de agua del litoral costero del Golfo de Cariaco están influenciadas por las condiciones: metereológicas, hidrodinámicas, hidrobiológicas, geoquímicas, geomorfológicas, ecológicas y por el influjo exógeno de origen antropogénico, por ser el receptáculo final de la escorrentía continental, alterando de una u otra forma el equilibrio hidrológico, biológico, geoquímico y ecológico (BonILla, 1982; BonILla, 1993). La hidrodinámica costera de la zona determina el drenaje de material dendrítico, orgánico e inorgánico que está en suspensión, hacia los ecosistemas litorales, siendo este hecho especialmente importante en la ecología, en la hidrobiológica y geoquímica marina, debido a que controla los cambios diagenéticos en la columna de agua y en los sedimentos marinos, proporcionando fuentes de energía, alimentos, vitaminas y minerales para las bacterias, flora y fauna (Bonilla et al., 1995).

Algunos metales trazas son esenciales y otros tóxicos, produciendo daños incalculables a la biota marina. Se consideran trazadores en la mezcla, y en la circulación de los océanos, no conservativos con períodos cortos de residencia, siendo componentes básicos de divergentes efluentes de origen antropogénico que se acumulan en los sedimentos costeros de una forma indiscriminada, degradando los ecosistemas, rompiendo el equilibrio ecológico y a su vez afectando temporalmente al Golfo de Cariaco por su hidrodinámica que lo caracteriza (GAMBOA \& Bonilla, 1983; Bonilla et al., 1995). Estudios sobre sedimentos en el Golfo de Cariaco son detallados en Bonilla \& Lin (1979), Bonilla (1982, 1993). Los procesos de convencción y afloramiento en el Golfo de Cariaco tienden a desarrollar fenómenos de renovación de las aguas superficiales pobres por aguas frías más profundas y ricas en sustancias nutritivas como nitritos, nitratos y fosfatos, estimulando el desarrollo fitoplanctónico junto a diferentes partículas de sedimentos que se depositan y se acumulan sobre la Plataforma Continental, constituyendo de esa manera la riqueza del fondo marino (Rowe et al., 1977; Bonilla et al., 1985). De igual manera, la descomposición de la materia orgánica ocasiona cambios geoquímicos importantes de los elementos biogenéticos contenidos en los sedimentos (relación $\mathrm{C}: \mathrm{N}: \mathrm{P}$ ), los cuales se correlacionan con los procesos de sedimentación y diagénesis (Bonilla et al., 1985)

El Golfo de Cariaco representa uno de los 5 sectores que conforman el área total de distribución y de pesca en el nororiente de Venezuela (SIMPSON \& GRIFFITHS, 1967; GuZMÁn et al., 1998; Quintero et al., 2002). El sector oriental del Golfo de Cariaco es considerado como un refugio de fauna, con una gran importancia desde el punto de vista socio-económico y ecológico, presentando la influencia de las descargas del río Carinicuao, quien desemboca en el sector más oriental del ecosistema. Para el mejor aprovechamiento del ecosistema del Golfo de Cariaco es necesario lograr condiciones óptimas de su medio ambiente, buena calidad de sus aguas y sedimentos, de acuerdo a su potencial hidrobiológico y geoquímico, para así poder obtener altos beneficios económicos y mayor cúmulo de conocimientos científicos para el crecimiento y producción regional del Estado Sucre, dentro del marco de la apertura petrolera.

En vista de la escasa información que existe en este importante ecosistema y en especial en el litoral norte del Golfo de Cariaco, se planteó en esta investigación estudiar algunos aspectos geoquímicos de los sedimentos del ecosistema, en base de las concentraciones de materia orgánica, permeabilidad, carbono orgánico, fósforo total, nitrógeno total, carbonato de calcio y de los metales Fe, $\mathrm{Mn}, \mathrm{Cu}, \mathrm{Cr}, \mathrm{Pb}, \mathrm{Ni}, \mathrm{Cd}$ y $\mathrm{Zn}$. Los resultados permitirán ampliar los conocimientos de calidad ambiental de los sedimentos y su posible grado de altercación.

\section{MATERIALES Y MÉTODOS}

\section{Área de Estudio.}

El Golfo de Cariaco es un ecosistema geográficamente semi-cerrado ubicado en la costa nororiental de Venezuela, específicamente, al este de la Cuenca de Cariaco, desde

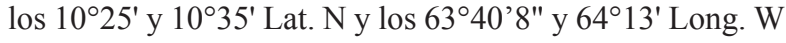
(Fig. 1).Tiene una longitud aproximada de $62 \mathrm{Km}$ en la dirección este-oeste y un máximo de $15 \mathrm{Km}$ de ancho en la dirección norte-sur, con un área aproximada de $642 \mathrm{Km}^{2}$ y un volumen estimado de $31,5 \mathrm{Km}^{3}$ (OKUDA, 1981). Está delimitado básicamente por dos formaciones: la espina dorsal de las penínsulas de Paría y Araya y las formaciones del Macizo Oriental. La primera está situada al norte del Golfo, hacia el sector occidental, en donde la mayoría de las elevaciones no alcanzan los $100 \mathrm{~m}$ de altura, con formaciones redondeadas y moldeadas por los procesos de erosión sobre las rocas esquistosas. Estas formaciones 
han permitido la creación de asentamientos humanos como: Manicuare, La Angoleta y otros. Más hacia el este, la fisiografía cambia, y el relieve de las montañas se hace más pronunciado, con paredes de acantilados rocosos que se hunden prácticamente dentro del Golfo, quedando expuestos a la erosión marina (CARABAllo, 1982). En el Golfo de Cariaco desembocan 79 cursos de agua, ríos, quebradas y riachuelos, de carácter intermitente. De estos, 34 corresponden a la costa sur y 45 a la costa norte. El río más importante de la región es el Manzanares, que descarga en la entrada del Golfo. En la costa sur entre los ríos de mayor influencia sedimentaria se encuentran, de oeste a este, los ríos: Tunantal, Guaracayal, Marigüitar, Tarabacoa, Cachamaure y Cariaco, los cuales han contribuido a la formaciónde los amplios deltas que se distribuyen a lo largo del litoral sur. En el sector norte, específicamente en la región centro-oriental, muchos de los cursos de agua tienen un recorrido de apenas $2 \mathrm{Km}$, no presentando zonas de planos aluviales, ni deltas, ya que, en la zona no existe un rasgo de plataforma que sirva de depositario a los sedimentos aportados desde la zona continental (Caraballo, 1982). La zona estudiada en la presente investigación comprendió el sector norte del Golfo de Cariaco (Fig. 1).

\section{Recolección de muestras}

Se recolectaron sedimentos superficiales en 13 sitios en el litoral nororiental del Golfo de Cariaco durante el mes de noviembre de 2002, utilizando para las mediciones de las coordenadas geográficas un GPS Marca Garmin 12 XL. Los sedimentos se recolectaron utilizando una draga tipo Diez Laffon de 0,02 $\mathrm{m}^{2}$ de área. Posteriormente fueron almacenadas en bolsas de polietileno a $-20^{\circ} \mathrm{C}$, hasta los análisis en los laboratorios del Departamento de Oceanografía del Instituto Oceanográfico de Venezuela, Universidad de Oriente. El secado de las muestras se realizó en una estufa P SELECTA a $80{ }^{\circ} \mathrm{C}$ hasta obtener un peso constante, luego se pulverizaron y homogenizaron en un mortero de porcelana, almacenándose posteriormente en envases de polietileno herméticamente cerrados.

\section{Análisis}

Todas las pesadas se realizaron en una balanza analítica marca Denver Instrument M-10 con precisión de 0,0001g. La permeabilidad de los sedimentos se determinó por pérdida de masa entre la muestra húmeda y la muestra secada $80^{\circ} \mathrm{C}$ en una estufa P SELECTA. La materia orgánica total fue calculada por diferencia de peso a través del método de calcinación a $540{ }^{\circ} \mathrm{C}$ descrito por DE LA LANZA (1980), Palenques \& Díaz (1994) y González \& Ramírez (1995). Para ello se utilizó una mufla Marca JELRUS.
El carbono orgánico fue analizado por el método de combustión húmeda (OKUDA, 1964), para ello se pesaron entre 0,1 y $0,5 \mathrm{~g}$ de sedimento y se añadió $10 \mathrm{ml}$ de agente oxidante (ácido sulfocrómico 0,4 mol. $1^{-1}$ ), se calentó hasta ebullición por 2 minutos y seguidamente, el exceso de $\mathrm{K}_{2} \mathrm{Cr}_{2} \mathrm{O}_{7}$ fue titulado con sal de Mohr 0,2 mol.1-1 (equivalente a $0,6 \mathrm{~g}$ de carbono orgánico). El carbonato de calcio se determinó por titulación volumétrica con $\mathrm{NaOH} 0,50$ mol.1 ${ }^{1}$ (Vogel, 1960). Para ello, se pesó 0,5 g de sedimentos previamente calcinados, se añadió $15 \mathrm{ml}$ de $\mathrm{HCl} \mathrm{0,1} \mathrm{mol.1-}$ ${ }^{1}$ y se calentó hasta ebullición. Las muestras se filtraron para eliminar la cantidad de sedimento que obstaculizaba el cambio de color del indicador en el punto final de la titulación y se valoró con $\mathrm{NaOH} 0,285 \mathrm{~mol}^{-1} \mathrm{l}^{-1}$, usando como indicador azul de bromofenol. El nitrógeno y el fósforo total fueron determinados por el método de VALDERRAMA (1981). Para los análisis de nitrógeno se utilizaron patrones certificados, Marine Nutrients Standards Kit (MNSK), en Ocean Scientific International Ltd, South Down House, Station Road, Petersfield, Hants GU32 3ET, Great Britain.

Los metales se determinaron por digestión ácida de $1 \mathrm{~g}$ de sedimento seco con una mezcla azeotrópica 3:1:1 de $\mathrm{HNO}_{3}, \mathrm{HCl}_{\text {y }} \mathrm{HClO}_{4}$ (LEwIS \& LANDING, 1992). Las lecturas se hicieron por Espectrofotometría de Absorción Atómica, utilizando un espectrofotómetro Perkin Elmer, modelo 3110. Para evaluar la calidad analítica de los datos obtenidos del análisis de los metales, se utilizó un patrón de sedimento certificado por la Enviromental Resource Associates: Catálogo número 540, lote 237 (Priority Pollutn/CPL. Soil). Los porcentajes de extracción de metales en las muestras estudiadas fueron bastantes representativos, tal como lo demuestran desviaciones estándar bastante bajas para las 5 réplicas analizadas y la comparación de los promedios obtenidos con el rango

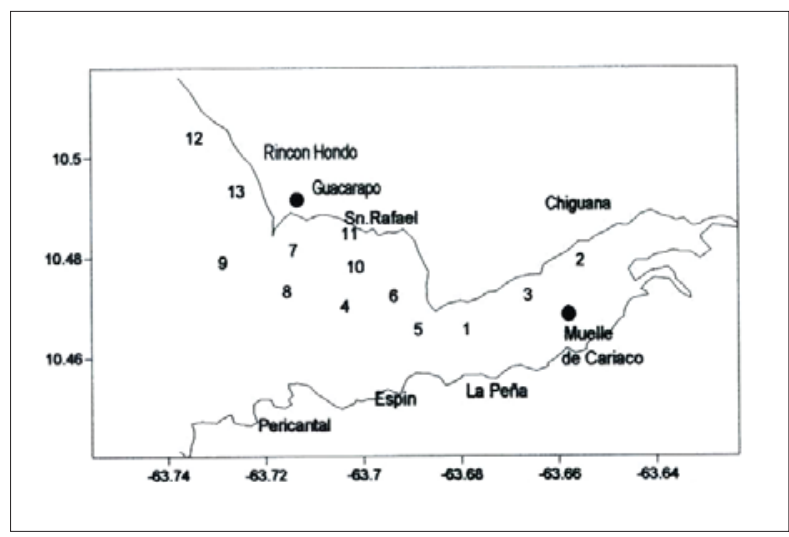

Fig. 1. Mapa del Golfo de Cariaco mostrando las estaciones de recolección de los sedimentos superficiales en el litoral nororiental. 
MARQUEZ ET AL

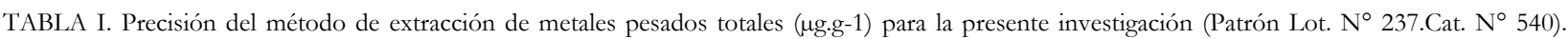

\begin{tabular}{lcccccccc}
\hline Muestia & $\mathrm{Fe}$ & $\mathrm{Zn}$ & $\mathrm{Mn}$ & $\mathrm{Cu}$ & $\mathrm{Cr}$ & $\mathrm{Ni}$ & $\mathrm{Cd}$ & $\mathrm{Pb}$ \\
\hline 1 & 798,36 & 87,27 & 110,8 & 106,73 & 81,73 & 51,56 & 48,09 & 70,87 \\
2 & 7996,69 & 87,78 & 111,96 & 106,83 & 80,59 & 52,4 & 48,08 & 69,12 \\
3 & 7991,32 & 87,49 & 110,61 & 106,37 & 81,43 & 51,71 & 48,04 & 69,58 \\
4 & 7990,86 & 88,12 & 113,51 & 107,89 & 81,58 & 51,3 & 48,89 & 71,47 \\
5 & 7993,86 & 86,98 & 111,39 & 107,21 & 81,36 & 51,36 & 47,45 & 72,00 \\
Promd. & 7990,82 & 87,53 & 111,654 & 107,006 & 81,338 & 51,666 & 48,11 & 70,608 \\
DS & 5,78 & 0,44 & 1,16 & 0,58 & 0,44 & 0,44 & 0,51 & 1,22 \\
R ang.Acept. & $2890-12600$ & $67,9-108$ & $101-154$ & $88,7-127$ & $70,5-106$ & $43,7-68,0$ & $40,3-64,5$ & $57,2-93,0$ \\
Valor Certif. & 7760,00 & 87,80 & 127,00 & 108,00 & 88,20 & 55,90 & 52,40 & 75,10 \\
\hline
\end{tabular}

Nota. C oncentraciones en $\mu g . g-1$

aceptable y el valor del patrón certificado (Tabla I). Toda el agua utilizada tanto en la preparación de reactivos, curvas de calibración y blancos de reactivos fue agua desionizada altamente pura (agua calidad NANOPURE de conductividad de $18 \mathrm{MÙ} / \mathrm{cm}$ ). Esto fue alcanzado con un sistema NANOPURE UV, Marca Barnstead. Al mismo tiempo, el material volumétrico de vidrio utilizado en el laboratorio fue de Clase A y los reactivos de Clase Analítica ultra pura. Para determinar asociaciones entre las estaciones se realizó análisis estadísticos de conglomerados, empleando el método de mínima varianza de Ward's y la distancia métrica Euclidiana. Para el análisis estadístico de los datos se utilizó el paquete estadístico STATGRAPHICS PLUS 4.1.

\section{RESULTADOS Y DISCUSIÓN}

\section{Carbono Orgánico (C-Org).}

El carbono orgánico en los sedimentos investigados presentó valores muy bajos (Tabla.II), distribuyéndose homogéneamente en toda la zona, evidenciándose por la desviación estándar bastante moderada $(0,70 \%)$. Los porcentajes de C-Org determinados variaron entre $0,06 \mathrm{y}$ $2,30 \%$ con media de $0,97 \%$, encontrándose una buena correlación de tipo lineal negativa con la materia orgánica total y los niveles de carbonato de calcio $(r=-0,54$ y $r=-$ $0,56)$, pero de forma lineal positiva con los compuestos de fósforo y nitrógeno $(\mathrm{r}=0,57 \mathrm{y} \mathrm{r}=0,74)$. El máximo valor $(2,30 \%)$ se detectó en la parte más litoral de San Rafael
(Est.10); sin embargo, porcentajes altos también se distribuyen desde la parte central de San Rafael hacia la zona de Guacarapo y Rincón Hondo, específicamente en las estaciones, 11,12 y $13(2,06 ; 1,39$ y $1,31 \%$ respectivamente). Estos valores son mayores a los reportados por López \& OKUdA (1968) para la laguna Grande del Obispo $(0,19 \%)$ y al contenido de $0,45 \%$ de los sedimentos del Archipiélago de los Roques (Bonilla et al, 2003a), pero comparables a los reportados por Bonilla et al. (1985) para los sedimentos de la región nororiental y río Orinoco $(4,29$ y 6,28 \%) respectivamente, así como, para los sedimentos ubicados en las cercanias del criogénico de Jose (1,86\%, Bonilla, 1993).

La relación positiva entre carbono orgánico, nitrógeno y fósforo total está bien documentada en trabajos de Oceanografía, puesto que hay una proporción o relación de átomos definidas (Relación de Redfield) en la cual se combina el carbono, nitrógeno y fósforo para formar la estructura de los organismos animales y vegetales (REDFIELD, 1942). Por su parte la relación de tipo negativa apreciada entre el carbono orgánico y la materia orgánica evidencia una heterogeneidad en la composición del sedimento, indicando la presencia de bajos niveles de carbono orgánico en su estructura. La pérdida de peso al someter la muestra a $540^{\circ} \mathrm{C}$ corresponde $\mathrm{a}_{2} \mathrm{O}$ de humedad $(105 \mathrm{~g} \mathrm{C})+\mathrm{H}_{2} \mathrm{O}$ de cristalización de hidróxidos $\left(300^{\circ} \mathrm{C}\right)+$ $\mathrm{H}_{2} \mathrm{O}$ de cristalización de arcillas $\left(540^{\circ} \mathrm{C}\right)+$ combustión de la materia orgánica $\left(500-540^{\circ} \mathrm{C}\right)+$ descomposición de 
carbonatos de $\mathrm{Fe}$ y $\mathrm{Mg}\left(540^{\circ} \mathrm{C}\right)$. Es por ello que probablemente halla existido pérdida de los compuestos volátiles presentes en el sedimento, generándose la relación de tipo negativa que es apreciada entre $\mathrm{C}$-org con la MOT y los carbonatos (Com. Pers. Armando Ramírez, UCV. Caracas). Acorde con estas observaciones, PÁEzOsunA et al. (1984) señalan que muestras con proporciones variables de minerales arcillosos que contienen agua estructural o interestructural pueden conducir a interpretaciones erróneas cuando las pérdidas de peso por ignición se utilizan como una medida del material orgánico. Es por ello que utilizar las pérdidas por ignición como una medida del material orgánico puede conducir a interpretaciones erróneas, cuando existen pequeñas diferencias en el contenido orgánico de muestras con proporciones variables de minerales arcillosos.

\section{Materia Orgánica total (MOT)}

La materia orgánica total se distribuyó en toda la zona con tendencia regular. Los valores variaron entre 1,53 y $14,70 \%$ con un promedio de 7,63 y DS $=4,45 \%$ (Tabla.II), determinándose los porcentajes más elevados entre las estaciones ubicadas en las cercanías de San Rafael, donde se determinaron porcentajes de $14 \%$ en la estación 6 y $14,70 \%$ en la 7 . Los valores más bajos fueron observados entre Rincón Hondo y Guacarapo (Est.13), donde los valores alcanzan $1,53 \%$. El resto de la zona bajo estudio presentó valores inferiores al $12 \%$. Los niveles de materia orgánica detectados en este trabajo, reflejan el tipo de grano sedimentario predominante y el grado de actividad biogeoquímica prevaleciente, el cual es indicativo de la productividad de la zona. Los niveles de materia orgánica encontradas en esta investigación, son comparables a los reportados Bonilla et al. (2003b) en los sedimentos bioclásticos del Archipiélago los Roques, los cuales presentan un contenido de materia orgánica con predominancia de material calcico. FuENTEs et al. (1997) reportó valores de 18,03\% de materia orgánica total de los sedimentos superficiales de la Laguna de Chacopata, indicando poca intervención antropogénica en la zona.

\section{Nitrógeno Total (NT)}

El NT se caracterizó por presentar una distribución de tendencia similar al fósforo total (PT) y a la razón NT/PT, con valores altos. El promedio de la zona fue de 396,29 $\mu \mathrm{g} \cdot \mathrm{g}^{-1}$, con Ds $=268,35$ distribuyéndose los valores mínimos en la zona más alejada del litoral, específicamente entre Chiguana y San Rafael donde se determinaron valores de $118,87 \mu \mathrm{g} \cdot \mathrm{g}^{-1}$ (Est.4) y 109,50 $\mu \mathrm{g} \cdot \mathrm{g}^{-1}$ (Est. 5). Los valores más elevados se detectaron entre las estaciones 10 y 11 donde las concentraciones alcanzaron 794,68 $\mu \mathrm{g} \cdot \mathrm{g}^{-1}$ y $837,83 \mu \mathrm{g} \cdot \mathrm{g}^{-1}$ respectivamente. Los altos contenidos de NT sugieren intensidad de procesos biogeoquímicos que prevalecen por la descomposición del material orgánico y por el aporte de diversos flujos de origen antropogénico que provenientes desde el litoral sur del Golfo, y que son transportados por las escorrentías límnicas. Los valores medios de nitrógeno total determinados en la costa norte del Golfo de Cariaco, son superiores al valor de 1,80 $\mu \mathrm{g} . \mathrm{g}$ ${ }^{1}$ indicados para los sedimentos de otros ecosistemas venezolanos, como los de la laguna de Chacopata (FuENTES et al., 1997) y al promedio $193,50 \mu \mathrm{g} . \mathrm{g}^{-1}$ reportado en la Laguna Grande del Obispo (Bonilla et al., 2003a).

\section{Fósforo Total (PT)}

En general el contenido de PT es muy alto con una distribución regular parecida a la del nitrógeno total. Las concentraciones variaron desde un mínimo de $114,19 \mu \mathrm{g} . \mathrm{g}^{-1}$ en las cercanías de la población de Chiguana (Est.3) hasta un máximo de $612,42 \mu \mathrm{g} . \mathrm{g}^{-1}$ en San Rafael (Est.11). El promedio general fue de $360,03 \mu \mathrm{g} . \mathrm{g}^{-1}$ y la desviación estándar 167,80. Los máximos se observaron hacia las estaciones 8 y 12 donde los valores oscilaron entre 421,15 y $612,42 \mu \mathrm{g} \cdot \mathrm{g}^{-1}$. En otros ecosistemas venezolanos, como la laguna de Las Marites, SALAZAR et al., (1986) reportaron promedios altos de fósforo total $\left(1230 \mu \mathrm{g} \cdot \mathrm{g}^{-1}\right)$, señalando impactos de origen antropogénico provenientes de la descarga exógena, aunado a excretas de aves que residen en la laguna. Fuentes et al. (1997) analizaron los sedimentos de la laguna de Chacopata, determinando un valor promedio de $600 \mu \mathrm{g} \cdot \mathrm{g}^{-1}$ indicando una asociación de este valor con las excretas de aves limnícolas, específicamente en las cercanías de los refugios de flamencos. En otros sitios, como la Laguna Grande del Obispo, Bonilla et al. (2003a) reportaron valores de 12,80 $\mu \mathrm{g} . \mathrm{g}^{-1}$ de fósforo total en los sedimentos de la mencionada ensenada; cantidades que son inferiores a las determinadas en la presente investigación.

MARCET et al. (1997) reportaron para los sedimentos de la Ría de Vigo concentraciones que oscilan entre 640 a $710 \mu \mathrm{g} \cdot \mathrm{g}^{-1}$, sugiriendo aportes simultáneos de las actividades de origen agrícola y urbano. Igualmente, DE LANZA \& CÁCERES (1984) indican que en general las altas concentraciones de PT obtenidas en los sedimentos de muchas lagunas mexicanas, reflejan la capacidad o característica particular de los sedimentos para retener el fósforo, tanto autóctono como exógeno que provienen de diversas fuentes antropogénicas, los cuales a su vez, favorecen procesos abióticos. 


\section{Relación Nitrógeno total/Fósforo total (NT/PT)}

En general la relación NT/PT estuvo delimitada por elevados contenidos de NT, siendo la especie química limitante, ya que los elementos de fósforo se degradan más rápidamente que los nitrogenados. Sin embargo, hubo zonas como el caso de las estaciones 1; 4; 5 y 6 en donde las concentraciones de fósforo fueron mayores que las de nitrógeno, sugiriendo deposiciones recientes.

Las relaciones NT/PT se distribuyeron regularmente con tendencia similar a la mostrada por los contenidos de NT y PT (Tabla II). Las fluctuaciones variaron entre 0,34 (Est.4) y 1,71 (Est.13) con promedio de 1,13 y DS $=0,43$, ubicándose los mayores valores desde el centro hasta la zona occidental (Ests. 7 hasta la 13). Estos valores determinados son inferiores a los reportados por BonILLA et al. (1985) para la zona nororiental de Venezuela, específicamente, el Golfo de Paría, Cuenca de Cariaco y río Orinoco $(2,28$ a 7,12). La diferencia existente ente los valores encontrados en este estudio y el de Bonilla et al. (1985), tiene su origen en la diferencia de la intensidad de los procesos abióticos que ocurren en las diferentes zonas estudiadas.

\section{Carbonato de Calcio $\left(\mathrm{CaCO}_{3}\right)$}

Los porcentajes de $\mathrm{CaCO}_{3}$ fueron variables y de tendencia bastante regular, presentando una correlación lineal negativa significativa con los compuestos de fósforo y nitrógeno $\left(\mathrm{R}^{2}=-0,57\right.$ y $\left.\mathrm{R}^{2}=-0,54\right)$. Los valores fueron inferiores al $60 \%$, a pesar que en el sedimento predominó la textura de tipo bioclástico arenoso con bajo contenido hídrico. El promedio determinado para la zona fue de 21,97 $\%$ con $\mathrm{DS}=17,01$. Los mínimos y máximos se detectaron cerca de San Rafael, en donde se determinaron porcentajes de $0,51 \%$ (Est.4) y 51,39 \% (Est. 6). Las estaciones 8-12, ubicadas entre Guacarapo y San Rafael, presentaron porcentajes inferiores al $12 \%$. Las concentraciones detectadas en el ecosistema bajo estudio, son inferiores a las reportadas por SALAZAR et al. (1986) en los sedimentos superficiales de la laguna de Las Marites (> 24,34 \%), los cuales presentan aportes biogénicos de conchas de moluscos. Similar característica es reportada para los sedimentos de la Ensenada Grande del Obispo, donde los valores de $\mathrm{CaCO}_{3}$ alcanzan 35,53 \% (Bonilla et al., 2003a). Por otra parte, los porcentajes de este estudio son inferiores a los reportados en otros ecosistemas venezolanos como la laguna de Chacopata, en el estado Sucre, en donde se observan promedios altos que alcanzan 45,64 \% (Fuentes et al., 1997). Bonilla et al. (1985), reportaron para los sedimentos de la región nororiental y río Orinoco, porcentajes altos de $\mathrm{CaCO}_{3}$ entre 30,28 y 43,90
$\%$, valores que están por encima de los determinados en esta investigación. En los sedimentos del Archipiélago de los Roques, Bonilla et al. (2003b) determinaron altas concentraciones de $\mathrm{CaCO}_{3}(99,02 \%)$, señalando un origen bioclástico de estos sedimentos. En otros ecosistemas mexicanos, como las lagunas de Huizache y Caimaneros, De la Lanza (1980), determiná bajos porcentajes de carbonato de calcio $(0,17$ a $3,89 \%)$, asociándolos a zonas de desecación existentes dentro de las lagunas, apreciándole de igual manera, que las máximas concentraciones se encontraban en las zonas inundadas de la laguna. Las concentraciones de $\mathrm{CaCO}_{3}$ en la costa norte del Golfo de Cariaco son comparables a los valores de 0 y 50 \% reportados por BERNAL \& BETANCOURT (1996), en los sedimentos de la Ciénaga Grande y Pajarales en Colombia.

\section{Contenido hídrico $\left(\mathrm{H}_{2} \mathrm{O}\right)$}

La distribución por estaciones del contenido hídrico es regular y diferente al comportamiento del $\mathrm{CaCO}_{3}$. Los sedimentos presentaron porcentajes de agua que varían de bajos a moderados, con promedio de $22,44 \%$, valores mínimos de 13, 79 \% en las inmediaciones de Rincón Hondo (Est.13) y máximos de 35, 84 en el sector San Rafael (Est.11). La desviación estándar fue de 6,97\%. De acuerdo al contenido de agua (Tabla II), los sedimentos bajo estudio se tipifican de textura arenosa gruesa a fina-limosa, característica que es atribuida a sedimentos de tipo biogénicos calcareníticos, los cuales pueden ser calificados como altamente permeables. Senior et al. (1999), caracterizaron los sedimentos del sector oriental del Golfo de Cariaco, señalando que la zona centro occidental presenta sedimentos de tipo arena-limo-arcilloso y que la zona costera de Guacarapo y El Chaure, presenta una dominancia de sedimentos arenosos. Señalan a su vez, que el sector más oriental del Golfo presenta un predominio de sedimentos arcillo-limoso que favorecen la acumulación de compuestos y elementos contaminantes, como aceites, grasas y metales pesados.

\section{Metales}

En Venezuela uno de los principales problemas al interpretar los resultados e indicar si un sedimento está contaminado, es que se carece de normativas internas que señalen valores considerados como contaminantes para los sedimentos fluviales y marinos, especialmente en la zona costera. En tal sentido, las comparaciones tienen que realizarse mediante valores reportados por autores en zonas que, inclusive, tienen características geomorfológicas diferentes a las encontradas en Venezuela. Las concentraciones de metales determinadas 
TABLA II. Porcentajes y concentraciones de las variables geoquímicas, orgánicas e inorgánicas en los sedimentos superficiales del litoral norte del Golfo de Cariaco, Estado Sucre, Venezuela.

METALES PESADOS

\begin{tabular}{|c|c|c|c|c|c|c|c|c|c|c|c|c|c|c|c|}
\hline $\mathrm{E}_{\mathrm{t}}$ & $\begin{array}{l}C-O_{\text {ग्य }} \\
\text { (\$) }\end{array}$ & $\begin{array}{l}\text { MOT } \\
\text { (\$) }\end{array}$ & $\begin{array}{c}\mathrm{NT} \\
\left(\mu_{\mathrm{Kag}} \mathrm{g}^{*}\right)\end{array}$ & $\begin{array}{c}\mathrm{PT} \\
\left(\mu \mathrm{T} \cdot \mathrm{g}^{4}\right)\end{array}$ & $\mathrm{CaCO}_{1}$ & $\mathrm{NT}^{\mathrm{T}} \mathbb{P} \mathrm{T}$ & $\begin{array}{l}\mathrm{H}_{2} \mathrm{O} \\
\text { (5) }\end{array}$ & ${ }_{\text {(Jueg) }}^{C u}$ & 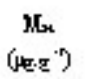 & $\underset{\left(\mu_{x g} g^{-1)}\right.}{Z x}$ & $\begin{array}{c}F_{\cdot} \\
\left(\mu \cdot g^{4}\right)\end{array}$ & $\begin{array}{c}\mathrm{ME} \\
\left(\mu_{\mathrm{Exg}}{ }^{*}\right)\end{array}$ & $\underset{(\text { Heg. }}{C d}$ & $\begin{array}{c}\mathrm{Pb} \\
\left(\mu \mathrm{g} \cdot \mathrm{g}^{4}\right)\end{array}$ & $\underset{\left(\mu \underline{\underline{g} g}{ }^{* 1}\right)}{G}$ \\
\hline 1 & 1,05 & 11,60 & 256,52 & 263,96 & 28,21 & 0,97 & 21,04 & 3,44 & 17,02 & 15,03 & 4172,49 & 12,51 & 1,24 & 0,00 & 10,73 \\
\hline 2 & 0,34 & 8,90 & 145,30 & $2 T 9,34$ & 38,58 & 0,52 & 21,53 & 2,21 & 11,01 & 9,52 & 2098,53 & $12,8 \mathrm{~T}$ & 1,50 & 1,96 & 8,53 \\
\hline 3 & 0,70 & 5,10 & $18 \mathrm{~T}, 53$ & 114,19 & 25,81 & 1,64 & 16,40 & 2,05 & 10,42 & 10,98 & 4366,80 & 10,95 & 0,74 & 0,00 & 10,51 \\
\hline 4 & 0,34 & 9,70 & $118,8 \mathrm{~T}$ & 346,74 & 0,51 & 0,34 & 18,86 & $1,4 T$ & 13,55 & 9,88 & $2049,2 T$ & 13,75 & 1,03 & 0,00 & 6,98 \\
\hline 5 & 0,06 & 11,90 & 109,50 & 215,28 & 44,29 & 0,51 & 17,12 & 2,20 & 16,06 & 11,85 & 3640,65 & $12,1 \mathrm{~T}$ & 1,38 & 1,45 & 11,11 \\
\hline 6 & 0,08 & 14,00 & 236,54 & 276,16 & 51,39 & 0,86 & 20,84 & 2,31 & 14,23 & 9,69 & 2303,32 & 12,85 & 1,81 & 3,02 & 7,82 \\
\hline$T$ & 0,95 & 14,70 & 456,94 & 378,85 & 37,82 & 1,21 & 18,29 & 2,64 & 14,18 & 11,98 & 3143,65 & 27,19 & 1,61 & 0,00 & 10,00 \\
\hline 8 & 1,25 & 4,20 & 500,78 & 421,15 & 3,99 & 1,19 & 18,89 & 2,15 & 19,80 & 12,23 & $5 T 45,2 \mathrm{~T}$ & 16,36 & 0,70 & 0,00 & 12,72 \\
\hline 9 & 0,76 & 1,90 & $T 5 T, \pi$ & 541,13 & $4,2 T$ & 1,40 & 23,60 & $1,0 T$ & $T, 12$ & 11,66 & 4486,36 & 17,60 & $0,3 T$ & 0,00 & 8,98 \\
\hline 10 & 2,30 & 4,90 & 794,68 & 584,72 & $8,9 T$ & 1,36 & 33,40 & 3,18 & 16,73 & 14,60 & 3936,54 & 10,97 & 0,71 & 0,00 & $13,8 \mathrm{~T}$ \\
\hline 11 & 2,06 & 6,000 & 837,83 & 612,42 & 11,95 & $1,3 T$ & 35,84 & 2,92 & 14,39 & 15,32 & 4091,12 & 11,65 & 0,76 & 0,00 & $14,9 \mathrm{~T}$ \\
\hline 12 & 1,39 & 4,70 & 538,24 & 522,92 & 9,46 & 1,03 & 32,16 & 2,95 & 12,86 & 13,51 & 3461,03 & 8,72 & 0,76 & 0,00 & 12,04 \\
\hline 13 & 1,31 & 1,53 & 211,20 & 123,49 & 20,38 & 1,71 & 13,79 & 1,12 & 22,89 & 4,36 & 1736,56 & 10,21 & 0,95 & 0,92 & 4,73 \\
\hline Man & 2,30 & 14,70 & 837,83 & 612,42 & 51,39 & 1,71 & 35,84 & 3,44 & 22,89 & 5,32 & $5 T 45,2 \mathrm{~T}$ & 27,19 & 1,01 & 3,02 & $14,9 \mathrm{~T}$ \\
\hline $\mathbf{M} x$ & 0,06 & 1,53 & 109,50 & 114,19 & 0,51 & 0,34 & 13,79 & $1,0 T$ & $T, 12$ & 4,36 & 1736,56 & 8,72 & 0,37 & 0,00 & 4,73 \\
\hline Pram & $0,9 \mathrm{~T}$ & 7,63 & 396,20 & 360,03 & $21,9 \mathrm{~T}$ & 1,09 & 22,44 & 2,20 & 14,63 & 11,59 & 3548,58 & 13,68 & 1,04 & $0,5 T$ & 10,23 \\
\hline DS & 0,70 & 4,45 & 268,35 & 167,80 & $1 T, 01$ & 0,43 & 6,97 & $0, \pi$ & 4,07 & 2,92 & 1109,55 & 4,70 & 0,43 & 0,99 & 2,85 \\
\hline
\end{tabular}

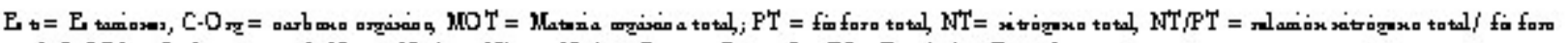

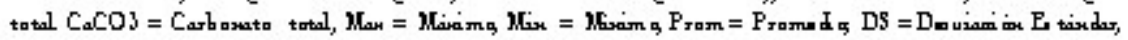

en esta investigación presentaron una distribución por estaciones, bastante uniforme en toda la zona, esto es evidenciado por las desviaciones estándar bastantes bajas $<4,70$, para todos los metales, con excepción de hierro que alcanzó desviaciones de 1109,55 (Tabla I). A su vez, el orden de la distribución apreciada fue: $\mathrm{Fe}>\mathrm{Mn}>\mathrm{Ni}>\mathrm{Zn}>\mathrm{Cr}>\mathrm{Cu}$ $>\mathrm{Cd}>\mathrm{Pb}$.

Cobre

Este metal se caracteriza como tóxico en altas 
concentraciones y de acción degradativa en los ecosistemas (SADIQ, 1992). Los valores de cobre (Tabla II) se distribuyeron regularmente, con tendencia uniforme y asociación positiva con los contenidos de $\mathrm{Cr}(\mathrm{r}=0,71)$. Las concentraciones oscilaron entre 1,07 y 3,44 $\mu \mathrm{g} . \mathrm{g}^{-1}$ con promedio de 2,29 $\mu \mathrm{g} \cdot \mathrm{g}^{-1}$ y DS $=0,75$. Los máximos niveles fueron apreciados entre Chiguana y San Rafael (Est. 1; 3,44 $\mu \mathrm{g} . \mathrm{g}^{-1}$ y Est.10; 3,18 $\left.\mu \mathrm{g} \mathrm{g}^{-1}\right)$. El resto del ecosistema presentó valores uniformes e inferiores a $3 \mu \mathrm{g} . \mathrm{g}^{-1}$. Mogollón et al. (1987) y Mogollón \& Bifano (1989), señalan valores de $24 \mu \mathrm{g} \cdot \mathrm{g}^{-1}$ de cobre para sedimentos no contaminados y de $60 \mu \mathrm{g} \cdot \mathrm{g}^{-1}$ para los contaminados. Por su parte SADIQ (1992) señala valores de $10 \mu \mathrm{g} . \mathrm{g}^{-1}$ para sedimentos no contaminados. El contenido medio de $\mathrm{Cu}$ (2, $\left.28 \mu \mathrm{g} \cdot \mathrm{g}^{-1}\right)$ determinado en los sedimentos del litoral nororiental del Golfo de Cariaco es inferior al señalado por estos autores, no reflejándose contaminación por este metal en la zona bajo estudio. Igualmente, los valores son bajos en comparación con los contenidos de cobre reportados por MARTínEZ (2002), quien señala valores promedios de $17,99 \mu \mathrm{g} . \mathrm{g}^{-1}$ para la costa norte, $5,49 \mu \mathrm{g} \cdot \mathrm{g}^{-1}$ para la costa sur y $14,25 \mu \mathrm{g} \cdot \mathrm{g}^{-1}$ para el transepto central del Golfo de Cariaco. Valores altos de $\mathrm{Cu}$, como producto de las actividades antropogénicas, han sido reportados en los sedimentos de la Laguna de Píritu, Estado Anzoátegui, Venezuela (Bonilla \& GonzÁlez (1992). Las concentraciones determinadas en la presente investigación son inferiores a los valores de $4,32 \mu \mathrm{g} \cdot \mathrm{g}^{-1}$ reportados para otros ecosistemas venezolanos como la laguna de Chacopata (FuENTES et al. 1997), a los señalados por Bonilla et al. (2003a) para los sedimentos biogénicos calcaríticos del Archipiélago de los Roques $\left(15,30 \mu \mathrm{g} \cdot \mathrm{g}^{-1}\right)$ y a los determinados por Acosta et al. (2002) en los sedimentos del litoral de Río Chico (11,52 $\left.\mu \mathrm{g} . \mathrm{g}^{-1}\right)$ y Boca Paparo $\left(46,10 \mu \mathrm{g} \cdot \mathrm{g}^{-1}\right)$, en Venezuela.

\section{Manganeso.}

La variación por estaciones de manganeso fue de tendencia diferente a la $\mathrm{Cu}$, presentando un gradiente y cierta discrepancia en las concentraciones, no evidenciándose relaciones de tipo lineal con los compuestos orgánicos e inorgánicos. Las concentraciones oscilaron entre 7,12 y $22,89 \mu \mathrm{g} . \mathrm{g}^{-1}$, con promedio de 14,63 $\mu \mathrm{g} . \mathrm{g}^{-1}$ y DS $=4,07 \mu \mathrm{g} \cdot \mathrm{g}^{-1}$. Los valores más elevados fueron observados, hacia los lados de Rincón Hondo (Est. 13), donde se detectan valores de $22,89 \mu \mathrm{g} . \mathrm{g}^{-1}$ y en la 8 donde se determinaron concentraciones de 19,80 $\mu \mathrm{g} \cdot \mathrm{g}^{-1}$.Estas concentraciones están influenciadas por aporte exógeno de origen antropogénico, trasladado desde la costa sur, debido a la hidrodinámica típica del Golfo de Cariaco. El valor promedio de $\mathrm{Mn}$ determinado en los sedimentos del ecosistema bajo estudio $\left(14,63 \mu \mathrm{g} . \mathrm{g}^{-1}\right)$ es inferior al reportado por GAMBOA \& Bonilla (1983) para los sedimentos de la Cuenca Tuy-Cariaco $\left(117,22 \mu \mathrm{g} \cdot \mathrm{g}^{-1}\right)$, al indicado por SALAZAR et al. (1986) en los sedimentos superficiales de la laguna de Las Marites $\left(94,57 \mu \mathrm{g} . \mathrm{g}^{-1}\right)$ y a las concentraciones reportadas por GAMBOA et al. (1986) para los sedimentos de la Bahía de Pertigalete $(20,42 \mu \mathrm{g} . \mathrm{g}$ $\left.{ }^{1}\right)$. Igualmente es bajo en comparación a los valores reportados por FuENTES et al. (1997) en los sedimentos de la laguna de Chacopata $\left(24,84 \mu \mathrm{g} \cdot \mathrm{g}^{-1}\right)$.

\section{Cinc}

La distribución por estaciones del metal $\mathrm{Zn}$ fue bastante heterogénea y de tendencia parecida a la del manganeso, pero diferente a la del cobre. Se detectó asociaciones positivas significativas con el cromo $(r=0,89)$ y los compuestos de fósforo $(r=0,65)$. Las concentraciones determinadas fueron bajas, presentando un máximo de $15,32 \mu \mathrm{g} \cdot \mathrm{g}^{-1}$ en la estación 11 (San Rafael) y el valor mínimo $\left(4,36 \mu \mathrm{g} \cdot \mathrm{g}^{-1}\right)$ en la 13 (San Rafael-Rincón Hondo). El valor medio fue de $11,59 \mu \mathrm{g} \cdot \mathrm{g}^{-1}$ y la DS $=2,92$. Las concentraciones más elevadas se detectaron desde la zona central hacia la occidental del litoral, específicamente entre las estaciones 1,5 y 7 y 12 , donde los contenidos de cobre presentan valores que oscilan entre 11,66 y $15,03 \mu \mathrm{g} \cdot \mathrm{g}^{-1}$. LEwIS \& LANDING (1992), indican que las concentraciones de $\mathrm{Zn}$ en el agua de los océanos son menores a $1,53 \times 10^{-3} \mu$ mol. $1^{-1}$, pero en áreas costeras y estuarios siempre son más altas debido a los aportes antrópicos de las aguas industriales y urbanas, pasando el metal a formar parte del sedimento. Mogollón \& Bifano (1989) señalan para sedimentos superficiales no contaminados de dos zonas del Lago de Valencia, valores promedios de $57 \mu \mathrm{g} \mathrm{g}^{-1}$ y de $146 \mu \mathrm{g} . \mathrm{g}^{-1}$ para los contaminados. Por otra parte, SADIQ (1992) señala para los sedimentos no contaminados concentraciones de $110 \mu \mathrm{g} \cdot \mathrm{g}^{-1}$. El valor medio de $\mathrm{Zn}\left(11,59 \mu \mathrm{g} \cdot \mathrm{g}^{-1}\right)$ determinado en esta investigación inferior a los reportados por estos autores para sedimentos contaminados e igualmente a las concentraciones indicadas por MARTíNEZ (2002) para la costa norte $\left(50,82 \mu \mathrm{g} . \mathrm{g}^{-1}\right)$, costa sur $(2,01$ $\left.116,64 \mu \mathrm{g} . \mathrm{g}^{-1}\right)$ y para transepto central del Golfo de Cariaco $\left(59,43\right.$ a $\left.222,42 \mu \mathrm{g} \cdot \mathrm{g}^{-1}\right)$.

\section{Hierro.}

La distribución de hierro por estaciones fue variable, detectándose gradientes en la concentración, con tendencia hacia valores altos, evidenciando aportes de tipo natural. Las concentraciones variaron entre 1736,56 y $5745,27 \mu \mathrm{g} \cdot \mathrm{g}^{-1}$, observándose un promedio elevado de $3548,58 \mu \mathrm{g} \cdot \mathrm{g}^{-1}$ con DS $=1109,55 \mu \mathrm{g} \cdot \mathrm{g}^{-1}$. Las estaciones 1,3 ubicadas en las cercanías de Chiguana y las estaciones 8 y 9 en las adyacencias de San Rafael, presentaron los 
valores más altos los cuales oscilaron cercanos al valor máximo. El promedio de hierro determinado en el sector de estudio, es superior a los valores reportados por SALAZAR et al. (1986) en los sedimentos de la laguna Las Marites $\left(1481,50 \mu \mathrm{g} \cdot \mathrm{g}^{-1}\right)$ y al valor $35,16 \mu \mathrm{g} \cdot \mathrm{g}^{-1}$ detectado por BonILLA et al. (2003a) en los sedimentos del Archipiélago Los Roques.

Well \& MAYer (1991) indican que el Fe, por encontrarse en grandes proporciones en la corteza terrestre, sus concentraciones suelen ser aportados en períodos de lluvia, incrementándose en los ambientes acuáticos bajo la influencia de la escorrentía de los ríos; los cuales constituyen una de las principales vías del transporte del hierro hacia los ecosistemas estuarinos y marinos, en donde es un micro nutriente esencial, llegando a ser un factor limitante para el crecimiento del fitoplancton.

RuBio et al. (1995) y RuBio et al. (2000) señalan que el hierro es un buen indicador de fuentes de entradas naturales y antropogénicas de metales ya que, asociaciones significativas de estos elementos con el hierro, es indicativo de fuentes de orígenes similares.

\section{Níquel.}

El contenido de níquel por estaciones fue relativamente alto, presentando valores entre 8,72 y $27,19 \mu \mathrm{g} \cdot \mathrm{g}^{-1}$, con promedio de $13,68 \mu \mathrm{g} \cdot \mathrm{g}^{-1}$ y Ds $=4,70$. No se apreciaron asociaciones de tipo lineal de este metal con los parámetros orgánicos e inorgánicos. La estación 7 ubicada en Guacarapo fue la de mayor concentración, determinándose valores inferiores a $17,60 \mu \mathrm{g} \cdot \mathrm{g}^{-1}$ en las demás estaciones. Mogollón \& Bifano (1989) indican como valor límite de 17 $\mu \mathrm{g} \cdot \mathrm{g}^{-1}$ para sedimentos no contaminados y $28 \mu \mathrm{g} \cdot \mathrm{g}^{-1}$ para los contaminados. Sin embargo, SADIQ (1992) señala que, los sedimentos no contaminados presentan valores inferiores a $10 \mu \mathrm{g}^{-\mathrm{g}^{-1}}$. En este estudio sólo en la estación 6 se determinó un valor alto de $27,19 \mu \mathrm{g} \mathrm{g}^{-1}$. El contenido medio de Ni $\left(13,68 \mu \mathrm{g} \cdot \mathrm{g}^{-1}\right)$ en los sedimentos de la zona estudiada es inferior a los valores de $22,80 \mu \mathrm{g} . \mathrm{g}^{-1}$ indicados por MARTínez (2002) para la costa norte y transepto central $\left(34,17 \mu \mathrm{g} . \mathrm{g}^{-1}\right)$ del Golfo de Cariaco, pero mayores a los de la costa sur $\left(10,29 \mu \mathrm{g} \cdot \mathrm{g}^{-1}\right)$. Sin embargo, los valores son comparables a los reportados por Fuentes et al. (1997) para los sedimentos de la laguna de Chacopata $\left(5,43 \mu \mathrm{g} \cdot \mathrm{g}^{-1}\right)$. Moore \& RAmammorthy (1984) señalan que el níquel ha venido siendo utilizado en la producción de fertilizantes de fosfato con fines agrícolas, lo que debe ser considerado como una importante fuente antrópica. Contenidos altos de níquel han sido reportados también por GAMBOA et al. (1986) en los sedimentos de influjo petrogénico y petroquímico de la Bahía de Bergantín $\left(45,60 \mu \mathrm{g} \cdot \mathrm{g}^{-1}\right)$ y por Bonilla \& GonzÁlez (1992) en los sedimentos contaminados de la laguna de Píritu, Estado Anzoátegui $\left(32,75 \mu \mathrm{g} \cdot \mathrm{g}^{-1}\right)$.

\section{Cadmio.}

Los valores fluctuaron entre un valor mínimo de 0,37 $\mu \mathrm{g} \cdot \mathrm{g}^{-1}$ en las cercanías de Guacarapo (Est. 9) y un máximo $1,81 \mu \mathrm{g} \cdot \mathrm{g}^{-1}$ en las adyacencias de San Rafael (Est.6). El valor promedio fue de $1,04 \mu \mathrm{g} \cdot \mathrm{g}^{-1}$ y DS $=0,43$. La tendencia presentada fue a asociarse positivamente y de forma significativa a la materia orgánica $(\mathrm{r}=0,88)$ y al carbonato de calcio $(r=0,87)$, confirmando las observaciones de Roux et al. (1998) y SADIQ (1992), quienes señalan que más del $50 \%$ del cadmio se encuentra asociado a los carbonatos y al contenido de materia orgánica. Se apreciaron correlaciones lineales negativas con el carbono orgánico $(r=-0,56)$, con los compuestos de fósforo $(r=$ $0,46)$ y nitrógeno $(\mathrm{r}=-0,59)$, así como con el hierro $(\mathrm{r}=$ 0,52). SADIQ (1992) señala que valores de $\mathrm{Cd}$ superiores a $1 \mu \mathrm{g} \cdot \mathrm{g}^{-1}$ indican contaminación en el sedimento. Valores superiores a los reportados por este autor fueron determinados en las estaciones. 1, 2 y 4 a 7 (1,03 a 1,61 $\left.\mu \mathrm{g} . \mathrm{g}^{-1}\right)$. En el resto de la zona los valores de $\mathrm{Cd}$ oscilaron entre 0,37 a 0,95 $\mu \mathrm{g} \cdot \mathrm{g}^{-1}$. En general, el Cd entra al ambiente marino por deposición atmosférica, escorrentías límnicas y a través de las descargas de afluentes de origen antropogénico, provenientes desde fuentes industriales y domesticas cercanas al litoral costero. El Cd en los ecosistemas marinos y lacustres se representa como uno de los metales pesados más contaminantes, siendo altamente tóxico en su estado de oxidación $\mathrm{Cd}^{2+}$.

Los resultados observados en este estudio corroboran las observaciones de MARTínez (2002) quien señala impactos de origen antropogénico para los sedimentos de la región norte $\left(1,58 \mu \mathrm{g} . \mathrm{g}^{-1}\right)$, sur $\left(1,20 \mu \mathrm{g} . \mathrm{g}^{-1}\right)$ y transepto central $\left(6,21 \mu \mathrm{g} . \mathrm{g}^{-1}\right)$ del Golfo de Cariaco. Por otra parte las concentraciones determinadas en esta investigación son comparables a la reportada por Acosta et al. (2002) para otras zonas de Venezuela, donde señalan valores inferiores a 1,0 $\mu \mathrm{g}_{\mathrm{g}} \mathrm{g}^{-1} \mathrm{de} \mathrm{Cd}$ en los sedimentos superficiales de Playa Güiria, 46,10 $\mu \mathrm{g}$. $\mathrm{g}^{-1}$ en Boca Paparo y concentraciones entre 23,70 $\mu \mathrm{g} \cdot \mathrm{g}^{-1} \mathrm{y} 1,28 \mu \mathrm{g} \cdot \mathrm{g}^{-1}$ en Río Chico, señalando un carácter degenerativo de estos ecosistemas.

KLAVINS \& ViRKaVs (2001) determinaron que en los sedimentos de pantanos en Latvia $18 \%$ que cadmio estaba asociado a los carbonatos, señalando que la afinidad del cadmio a la fracción de carbonatos determina el potencial impacto de este elemento sobre los procesos biológicos 
y el medio ambiente acuático. En esta investigación se aprecia también una afinidad de este metal por los carbonatos, corroborando las observaciones de estos autores. En muchos ecosistemas se han reportado efectos adversos de las concentraciones de $\mathrm{Cd}$ sobre la reproducción de las especies acuáticas, tal es el caso de la Bahía de San Francisco, en donde algunas especies como las almejas, presentaron síntomas negativos en su fisiología, como producto del incremento de $\mathrm{Cd}$ sedimentario desde $0,1 \mu \mathrm{g} \cdot \mathrm{g}^{-1}$ hasta $0,4 \mu \mathrm{g} \cdot \mathrm{g}^{-1}$ (LuOMA et al., 1990).

La detección de altos contenidos de $\mathrm{Cd}$ en los sedimentos del ecosistema del litoral nororiental del Golfo de Cariaco, evidencian aportes por la influencia de alta incidencia antropogénica. MARTínez (2002) señala que la costa norte del Golfo de Cariaco es la menos densa poblada y carente de actividades industriales; sin embargo, debido a la hidrodinámica del Golfo, los contaminantes provenientes desde las empresas ubicadas en la costa sur son llevados hacia el centro y la costa norte. Igualmente la circulación ciclónica presente en el Golfo, la cual ha sido señalada por GADE (1961), podría estar trasladando altos niveles de cadmio desde la costa sur hacia la norte.

\section{Plomo.}

Se determinaron valores bajos en la mayoría de la zona estudiada que variaron entre no detectado y 3,02 $\mu \mathrm{g} \cdot \mathrm{g}^{-1}$ en las cercanías del sector San Rafael (Est.6). Las concentración promedio fue de $0,57 \mu \mathrm{g} \cdot \mathrm{g}^{-1}$, determinándose valores moderados para las estaciones $2\left(1,96 \mu \mathrm{g} . \mathrm{g}^{-1}\right)$ y 5 $\left(1,45 \mu \mathrm{g} \cdot \mathrm{g}^{-1}\right)$, ubicadas en el transepto Chiguana-San Rafael. La distribución de $\mathrm{Pb}$ por estaciones fue similar a la del $\mathrm{Cd}$, evidenciándose por la relación positiva altamente significativa entre ambos metales $(r=0,71)$, sugiriendo orígenes similares. Se detectó asociación del cadmio con el carbono orgánico $(\mathrm{r}=0,57)$ y el carbonato de calcio $(\mathrm{r}=$ $0,75)$.

Moore \& Ramammorthy (1984) y SADIQ (1992) indican que las actividades humanas son las fuentes principales de la contaminación por este elemento y que niveles inferiores a $5 \mu \mathrm{g} . \mathrm{g}^{-1}$ son considerados como no contaminantes. Las concentraciones determinadas en este estudio son bajas en comparación a las reportadas por estos autores, no reflejando impacto por $\mathrm{Pb}$ en el ecosistema estudiado. Los valores determinados son inferiores a los indicados por MARTínEz (2002), para la costa norte $\left(17,99 \mu \mathrm{g} \cdot \mathrm{g}^{-1}\right)$, para la costa sur $\left(14,26 \mu \mathrm{g} \cdot \mathrm{g}^{-1}\right)$ y en el transepto central del Golfo de Cariaco $\left(30,06 \mu \mathrm{g} \cdot \mathrm{g}^{-1}\right)$. Señala el autor la existencia de aportes de este metal provenientes de la circunnavegación debido al gran tráfico de embarcaciones con motores fuera de borda.

\section{Cromo.}

La distribución de las concentraciones de $\mathrm{Cr}$ por estaciones fue variable presentando valores que varían entre 4,73 y $14,97 \mu \mathrm{g} . \mathrm{g}^{-1}$ con una media $10,23 \mu \mathrm{g} \cdot \mathrm{g}^{-1}$ y DS $=2,85$. Se observaron valores moderados que oscilaron entre 10,51 y $11,11 \mu \mathrm{g} \cdot \mathrm{g}^{-1}$ para las estaciones ubicadas en la zona más oriental (Ests.1, 3, 5), zona central de la costa norte (Est. 8) y algunas ubicadas en la parte más occidental (Ests. 9 y 12) los demás sitios presentaron concentraciones inferiores a los $10 \mu \mathrm{g} \cdot \mathrm{g}^{-1}$. La principal fuente de contaminación por cromo en las aguas naturales y sedimentos son los efluentes domésticos e industriales provenientes de los procesos de acabados industriales. En este estudio las concentraciones determinadas muestran diferentes orígenes, como se evidencia por las diferentes asociaciones de tipo lineal positiva que presenta este metal con el carbono orgánico $(r=0,54)$, fósforo y nitrógeno $(r=0,64)$ y con los metales hierro y cinc $(r=0,73$ y r $=0,89)$.

SAdiQ (1992), señala que en los sedimentos no contaminados los valores de cromo son inferiores $20 \mu \mathrm{g} . \mathrm{g}^{-1}$. Los resultados obtenidos en este trabajo son inferiores a estas concentraciones, no evidenciándose contaminación por este metal. Los valores medios de $10,23 \mu \mathrm{g} \cdot \mathrm{g}^{-1}$ obtenidos en esta investigación son inferiores a los reportados por MARTínEZ (2002) para la costa norte $(36,89$ $\left.\mu \mathrm{g} . \mathrm{g}^{-1}\right)$, para la costa sur $\left(16,12 \mu \mathrm{g} \cdot \mathrm{g}^{-1}\right)$ y para el transepto central $\left(76,17 \mu \mathrm{g} \cdot \mathrm{g}^{-1}\right)$ del Golfo de Cariaco. Acosta et al. (2002), indican valores de cromo en los sedimentos superficiales de Boca Paparo en el orden de 47,50 $\mu \mathrm{g} \cdot \mathrm{g}^{-1} \mathrm{y}$ de 3,80 $\mu \mathrm{g} \cdot \mathrm{g}^{-1}$ en la zona de Río Chico. Mogollón et al. (1987) reportaron valores altos de $\mathrm{Cr}$ varían de $84 \mu \mathrm{g} . \mathrm{g}^{-1}$ para los sedimentos contaminados de la costa de de Puerto la Cruz, Estado Anzoategui y 118,00 $\mu \mathrm{g}^{-\mathrm{g}^{-1}}$ en Pertigalete, así como, $135 \mu \mathrm{g} \cdot \mathrm{g}^{-1}$ en la Bahía de Barcelona, en el estado Anzoátegui.

El cromo, específicamente en su estado $\mathrm{Cr}$ (III) es un micro nutriente traza esencial en bajas concentraciones, siendo su forma como Cr (VI) la más tóxica. La mayor parte del $\mathrm{Cr}$ correspondiente a los sedimentos acuáticos se encuentra en la forma trivalente $y$, a pesar de no ser tan móvil en el medio ambiente como el $\mathrm{Cr}$ (VI), se ha estudiado en forma experimental su acumulación y movimiento hacia los eslabones superiores de la cadena alimentaria (AISLABIE \& LOUTIT, 1986; BREMER \& LOUTIT, 1986). La información acerca de los efectos de los niveles sobre la flora y fauna 


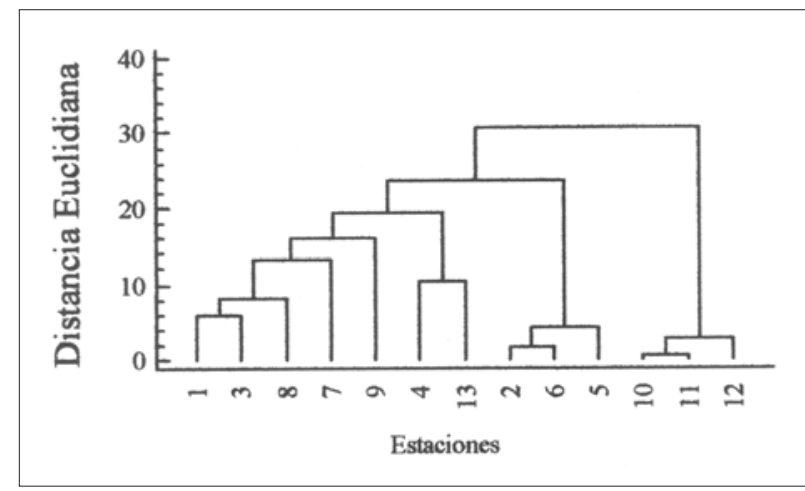

Fig.2. Dendograma de similitud que muestra la asociación entre los parámetros geoquímicos orgánicos e inorgánicos en los sedimentos superficiales del litoral norte del Golfo de Cariaco, Venezuela.

acuática, los peces y las aves zancudas y detritófagas es limitada. No se sabe con certeza el mecanismo por el cual el Cr ligado a los sedimentos, llega a los tejidos de animales y plantas (STEPHENSON, 1998). Hay evidencias de que ocurre acumulación de $\mathrm{Cr}$ en organismos bentónicos como, conchas coquinas, poliquetos y caracoles después de la exposición a sedimentos contaminados con $\mathrm{Cr}$, tal como ocurrió en Sawyer, Nueva Zelanda (Aislabie \& Loutit, 1986).

El análisis estadístico de conglomerados (Fig.2) muestra cierto grado de homogeneidad entre las 13 estaciones estudiadas, con grupos conformados por las asociaciones entre las estaciones pertenecientes a la zona del lado este (Ests.1 y 3) con algunas situadas en la zona central del litoral nororiental del Golfo (Est.8). El mismo fenómeno se observa entre la estación 4, la cual se encuentra ubicada en la zona central y la estación 13 situada en la parte occidental de la zona bajo estudio. Un grupo formado por las estaciones 10,11 y 12 , al igual que el conformado por las estaciones 2,6 y 5 muestran características parecidas en la distribución.

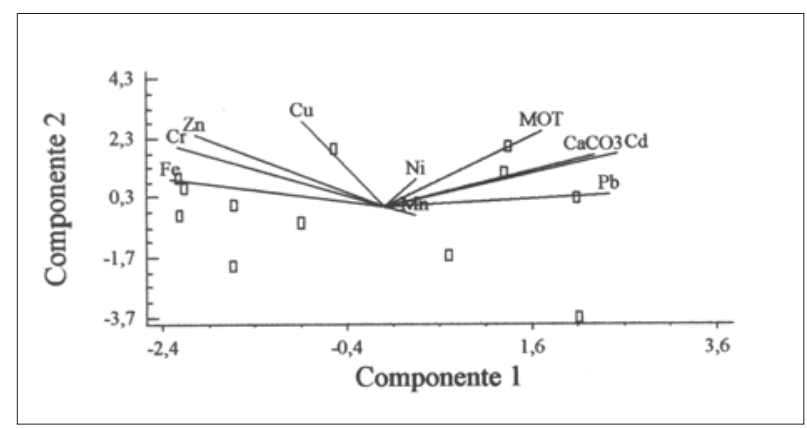

Fig.3. Representación gráfica entre metales con la materia orgánica total y carbonato de calcio para los dos primeros componentes principales.
Tabla III. Componentes principales de las variables geoquímicas, orgánicas e inorgánicas en los sedimentos superficiales del litoral nororiental del Golfo de Cariaco, Estado Sucre, Venezuela.

\begin{tabular}{lccc}
\hline & \multicolumn{3}{c}{ COMPONENTES } \\
\hline $\mathrm{CaCO}$, & 1 & 2 & 3 \\
$\mathrm{Cd}$ & 0,38 & 0,30 & 0,06 \\
$\mathrm{Cr}$ & 0,42 & 0,31 & 0,006 \\
$\mathrm{Cu}$ & $-0,37$ & 0,35 & 0,14 \\
$\mathrm{Fe}$ & $-0,15$ & 0,51 & 0,31 \\
$\mathrm{Mn}$ & $-0,30$ & 0,16 & $-0,12$ \\
$\mathrm{MOT}$ & 0,06 & $-0,06$ & 0,54 \\
$\mathrm{Ni}$ & 0,20 & 0,45 & $-0,16$ \\
$\mathrm{~Pb}$ & 0,06 & 0,15 & $-0,71$ \\
$\mathrm{Zn}$ & 0,41 & 0,07 & 0,21 \\
& $-0,34$ & 0,42 & $-0,01$ \\
\%VE & & & $\mathbf{1 3 . 2 3}$ \\
\%VA & $\mathbf{4 0 , 0 4}$ & $\mathbf{2 7 , 3 0}$ & $\mathbf{5 0 , 5 7}$ \\
\%VE = Porcentaje de variable explizatima & \\
\%VA = Porontaje de variable acumula da & \\
\hline
\end{tabular}

Por otra parte, el análisis de factores aplicado a las variables geoquímicas, en función de los componentes principales, muestra que los tres primeros componentes explican el 80,57\% de las diferentes variables geoquímicas en el litoral de la costa norte del Golfo de Cariaco (Tabla. III). El primer componente es el de mayor varianza (40,04\%), siendo el de mayor peso para explicar la totalidad de las variables estudiadas. En el plano ortogonal (Fig.3) el cadmio y el plomo se correlacionan con la materia orgánica y el carbonato de calcio en forma positiva al primer componente, siendo grande la interacción entre el cadmio y carbonato. Manganeso y níquel no contribuyen a explicar la interpretación del análisis, por encontrarse muy cercano al origen de la representación gráfica. El primer componente, a su vez, muestra un contraste entre los metales, $\mathrm{Cr}, \mathrm{Cu}, \mathrm{Fe}$ y $\mathrm{Zn}$ (signos -) con las demás variables. En el segundo componente, el cual tiene una varianza explicativa de $27,30 \%$, evidencia una discrepancia muy fuerte entre el Mn y el resto de las variables; sin embargo, se aprecia una asociación significativa entre los metales $\mathrm{Cr}, \mathrm{Zn}$ y Fe, no presentando el cobre correlación de ningún tipo con estos metales. Estas observaciones pueden ser explicadas a partir de $67,34 \%$ de la varianza acumulada y evidencian fuentes de origen similares para estos metales. 
En el tercer componente se establecen diferencias entre $\mathrm{Fe}, \mathrm{MOT}, \mathrm{Ni}$ y $\mathrm{Zn}$ con el resto de las variables, siendo esto explicado a partir de 13,23\% de varianza. Lo apreciado en el análisis de componentes principales es corroborado con lo apreciado en los coeficientes de correlación lineal obtenidos a través de la matriz de correlación de Pearson, en donde se establecen relaciones bastantes significativas desde el punto de vista estadístico entre $\mathrm{Pb}$ y $\mathrm{Cd}(\mathrm{r}=0,71)$, entre el $\mathrm{Cu}$ con el $\mathrm{Zn}$ y $\mathrm{Cr}(\mathrm{r}=0,78$ y r $=0,71)$, sugiriendo fuentes de orígenes similares. En tanto hay una fracción de $\mathrm{Zn}, \mathrm{Pb}$ y $\mathrm{Cr}$ que por encontrarse asociada en forma lineal positiva con el hierro $(\mathrm{r}=0,65 ; \mathrm{r}=0,50$ y 0,73$)$, tendrían su origen en la deposición de estas trazas sobre los oxihidróxidos de hierro presentes en la zona estudiada.

\section{CONCLUSIONES}

En general se observó una tendencia de todos los parámetros orgánicos e inorgánicos a acumularse en las estaciones más próximas a la zona litoral, específicamente en las adyacencias del sector San Rafael. Los sedimentos son texturizados como arenosos por ser permeables, con valores bajos en las concentraciones de C-Org y MOT y altos de las especies nitrogenadas y fosforadas, en comparación con otras zonas costeras venezolanas, lo cual indica gran incidencia de los procesos abióticos.

La distribución de las concentraciones de los metales evaluados presentaron el orden: $\mathrm{Fe}>\mathrm{Mn}>\mathrm{Ni}>\mathrm{Zn}>\mathrm{Cr}$ $>\mathrm{Cu}>\mathrm{Cd}>\mathrm{Pb}$, no detectándose contaminación, a excepción del cadmio. La mayoría de estos elementos, con excepción del Cd, presentan niveles bajos, siendo las concentraciones inferiores a los contenidos reportados por otros autores para sedimentos no contaminados. Se observaron asociaciones entre los porcentajes de carbonatos y materia orgánica, con los niveles de cadmio, plomo y a su vez, entre las concentraciones de nitrógeno y fósforo total. Los niveles de cromo, cinc, cobre y hierro también estuvieron asociados entre si.

La asociación del plomo y cadmio con la materia orgánica, podría producir una eventual liberación hacia la columna de agua, si las condiciones de óxido reducción del medio son alteradas, lo cual podría generar en el futuro, efectos adversos al ecosistema del Golfo de Cariaco.

RuBio et al. (1995) y RuBio et al. (2000) señalan que la relación de tipo lineal que presentan algunos metales pesados como los estudiados en esta investigación, con el hierro indican fuentes similares. Sin embargo, la relación no lineal presentada por el $\mathrm{Pb}, \mathrm{Cu}, \mathrm{Ni}, \mathrm{Mn}$, con el Fe, sugiere la existencia de una fuente exógena de origen antropogénico que pudiera estar originando la entrada de estos metales al Golfo de Cariaco. Esta fuente posiblemente tengan origen en las descarga de los ríos que desembocan en esta zona, vertimientos de actividades industriales y las embarcaciones que transitan por la zona, aunado al flujo antrópico unidireccional transportado por la hidrodinámica del Golfo desde la costa sur.

\section{AGRADECIMIENTO}

Los autores agradecen al Postgrado de Ciencias Marinas del Instituto Oceanográfico de Venezuela, UDO y a la Dirección del Instituto por todo el apoyo logístico brindado para la realización del muestreo de los sedimentos.

\section{REFERENCIAS}

Acosta, V., C. Lodeiros., W. Senior. \& G. Martínez. 2002. Niveles de metales pesados en sedimentos superficiales en tres zonas litorales de Venezuela. Interciencia. 27 (12): 686-690

Aislabie, J. \& M. Loutit. 1986. Accumulation of Cr (III) by bacteria isolated from polluted sediment. Mar .Envir. Res. 20: 221-232.

Bermúdez, P. 1966. Consideraciones sobre los sedimentos del Mioceno Medio al reciente de las costas centrales y orientales de Venezuela. Bol. Geol. Caracas. 7: 333412.

Bernal, G. \& J. Betancourt.1996. Sedimentología de lagunas costeras: Ciénaga Grande de Santa Marta y Ciénaga de Pajarales. Bol. Invest. Mar. Cost. 25: 49-76.

Bonilla, J. \& A. Lin.1979. Materia orgánica de los sedimentos superficiales del Golfo de Paría y Cariaco, Venezuela. Bol. Inst. Oceanogr. Venezuela. Univ. Oriente. 18 (1\&2):37-52

.\& C. GonzÁlez. 1992. Algunos aspectos geoquímicos de los sedimentos de la Laguna de Píritu, Edo. Anzoátegui.Venezuela. Bol. Inst. Oceanogr. Venezuela. Univ. Oriente. 31 (1\&2):27-44.

1982. Algunas características geoquímicas de los sedimentos superficiales del Golfo de Cariaco, Venezuela. Bol. Inst. Oceanogr. Venezuela. Univ. Oriente. 18 (1\&2):133-155. 
1993. Características hidroquímicas: Comportamiento y significados de modelos estadísticos multivariantes en el bi ecosistema marino Costero de Jose, Edo. Anzoátegui. Trab. de Ascenso a Prof. Titular. Inst. Oceanogr. Univ. Oriente. 231 pp.

A. Márquez. \& B. Gamboa. 1985. Características geoquímicas en núcleos de sedimentos de la región nororiental y río Orinoco Venezuela. Oceanogr. Univ. Oriente.24 (1-2): 43-61.

J. Fermín, J., B. Gamboa. \& M. Cabrera. 1995. Aspectos geoquímicos de los sedimentos superficiales ecosistema marino costero de Jose. Edo. Anzoátegui, Venezuela. Bol. Inst. Oceanogr. Venezuela. Univ. Oriente. 32 (1\&2): 5-23.

J. MoyA. \& A. Quintero. 2003b. Contenido orgánico y parámetros reductores de sedimentos del Archipiélago Los Roques, Venezuela. Bol. Inst. Oceanogr. Venezuela. Univ. Oriente. 42 (1\&2):47-63.

., S. Aranda, C. Ramírez., J. Moya. \& A. Márquez. 2003a. Calidad de los sedimentos superficiales de la Ensenada Grande del Obispo, Estado SucreVenezuela. Bol. Inst. Oceanogr. Venezuela. Univ. Oriente. 42 (1\&2):3-27.

Bremer, P. \& M. Loutit. 1986. Bacterial polysaccharide as a vehicle for entry of $\mathrm{Cr}$ (III) to a food chain. Mar. Envir. Res.20: 235-248.

Caraballo, L. 1982. El Golfo de Cariaco. Parte I. Morfología y batimetría submarina. Estructura y Tectonismo reciente. Bol. Inst. Oceanogr. Univ. Oriente. 21 (1\&2):13-35.

De la Lanza, G. \& C. CÁceres. 1984. Lagunas Costeras y el Litoral Mexicano. Universidad Autónoma de Baja California Sur (Ed). 525 pp.

De la LanZA, G. 1980. Materia orgánica en una laguna de la costa de Sinaloa, México (I): Cuantificación total. Bol. Inst. Oceanogr. S. Paulo. 29 (2): 217-222.

Fuentes, M., J. Bonilla, J \& J. Fermín. 1997. Algunas características químicas de los sedimentos superficiales de la Laguna de Chacopata, Estado Sucre. Venezuela. Bol. Inst. Oceanogr. Venezuela. Univ. Oriente. 36 (1\&2).69-79.
GADE, H. 1961. Further hydrographic observations in the Gulf of Cariaco, Venezuela. The circulations and water exchange. Bol. Inst. Oceanogr. Venezuela. Univ. Oriente. 1(2):356-395.

GamboA, B. \& J. Bonilla. 1983. Distribución de metales ( $\mathrm{Fe}, \mathrm{Mn}, \mathrm{Cu}, \mathrm{Zn}$ ) en sedimentos superficiales de la Cuenca Tuy-Cariaco. Bol. Inst. Oceanogr. Venezuela. Univ. Oriente. 22 (1-2): 103-110.

, J. Bonilla, \& G. CeneÑo.1986. Concentración de algunos metales pesados en sedimentos superficiales de la Bahía de Pozuelos y áreas adyacentes, Estado Anzoátegui. Venezuela. Bol. Inst. Oceanogr. Univ. Oriente. 25 (1-2): 233-240.

GonzÁlez, H. \& M. Ramírez. 1995. The effect of nickel mining and metallurgical activities on the distribution of heavy metals in Levisa Bay, Cuba. J. Geochem. Explorat. 52: 183-192.

Guzmán, R., G. Gómez. \& M. Penott. 1998. Aspectos Biológicos y Pesquería de la sardina (Sardinilla aurita) en el Golfo de Cariaco, Venezuela. Zootec. Trop. 16(2): 149-162.

Klavins, M. \& M. Vircavs. 2001. Metals in sediments of inland waters of Latvia. Boreal. Envir. Res. 6:297306.

LEWIS, B. \& W. LANDIG. 1992. The investigation of dissolved and suspended particulate trace metals fractionation in the Black Sea. Mar. Chem. 40: 105-141.

LÓPEZ, M. \& T. OKUDA. 1968. Algunas observaciones sobre las características físicoquímicas de los sedimentos y distribución de la fauna macro bentónita de la laguna Grande del Obispo (Venezuela). Bol. Inst. Oceanogr. Univ. Oriente. 7 (1): 107-127.

Luoma, S., R. Dagovitz. \& E. Axtmann. 1990. Temporally intensive study of trace metals in sediments and bivalves from a large river-estuarine system: Suisun Bay/Delta in San Francisco Bay. The Science of the Total Environment. 97/98, 685-712.

Macsotay, O. \& L. Caraballo. 1976. Biología y Estratigrafía Cenozoica de la parte Oriental del Golfo de Cariaco. Edo. Sucre Venezuela. Bol. Inst. Oceanogr. Univ. Oriente.15: 1925-56. 
Marcet, P., M. Andrade \& L. Montero, L. 1997. Contenido y enriquecimiento de metales en sedimentos de la Ría de Vigo (España). Thalassas. 13: 87-97.

Martínez, G. 2002. Metales pesados en sedimentos superficiales del Golfo de Cariaco, Venezuela. Bol. Inst. Oceanogr. Venezuela. Univ. Oriente. 41: (1\&2). 83-96.

Mogollón, J. \& R. Bifano. 1989. Contaminación por $\mathrm{Cu}$, $\mathrm{Ni}, \mathrm{Zn}$, en sedimentos de la Cuenca del Lago de Valencia. Acta. Cient. Vzla. 40: 157-158.

Mogollón, T., H. Freintzein \& C. Bifano. 1987. Contaminación en sedimentos de la Cuenca del río Tuy y controles geoquímicos que actúan en el sistema. Acta. Cient. Vzla. 38:47-58.

Moore, J. \& S. Ramammorthy. 1984. Heavy Metal in Natural Waters. Pergamon Press. Gran Bretaña. 268 pp.

OKudA, T. 1964. Some problems for the determination of organic carbon in marine sediments. Bol. Bol. Inst. Oceanogr. Univ. Oriente. 3 (1 \&2) 106-117

1981. Water exchange and the balance of phosphate in the Gulf of Cariaco, Venezuela. Coast. Estuar. Scienc.1: 274-281.

Palangues, A. \& J. Díaz. 1994. Anthropogenic heavy metal pollution in the sediments of the Barcelona continental shelf (Northwestern Mediterranean). Mar. Envir. Res. 38: 17-31.

Paez-Osuna, F., M. Fong-Lee \& H. Fernández-Pérez.1984. Comparación de tres técnicas para analizar materia orgánica en sedimentos. An. Inst. Ciencias del Mar y Limnol UNAM. México. 11 (1): 257-264.

Quintero A., G. Terejova, G. Vicent., A. Padrón \& J. Bonilla. 2002. Los pescadores del Golfo de Cariaco. Interciencia.27 (6) 286-292.

Redfield, A., B. Ketchum \& F. Richards. 1963. The Influence of Organisms on the Composition of Sea Waters. In Hill, MN (Ed.), The Sea, Vol 2. WilleyInter science, New York, 26-77 pp.

Roux, L., S. Le Roux. \& P. Appriou. 1998. Behavior and speciation of metallic species $\mathrm{Cu}, \mathrm{Cd}, \mathrm{Mn}$ and $\mathrm{Fe}$ during estuarine mixing. Mar. Pollu. Bull. 36 (1): 5664.

Rowe, G., C. Clifford. \& K. Smithz. 1977. Nutrient regeneration in sediments of Cap. Blanca Spanish Sahara. Deep. Sea. Res. 24:47-63.

Rubio, B., M. Nombela \& F. Vilas. 2000. Geochemistry of majors and trace elements in sediment of the Ria de Vigo (NW Spain): an assessment of metal pollution. Mar. Poll. Bull. 40 (11): 968-980.

Nombela, F. Vilas, I. Alejo, S. García-Gil, E. García-Gil \& O. Pazos. 1995. Distribución y enriquecimiento de metales pesados en sedimentos actuales de la parte interna de la Ría de Pontevedra. Thalassas.11: 35-45.

SAdiQ, M. 1992. Toxic Metal Chemistry in Marine Environments. Marcel Dekker Inc., New York: 389 pp.

Salazar, J., J. Bonilla \& B. Gamboa. 1986. Metales pesados y materia orgánica en los sedimentos superficiales de la Laguna Las Marites. Bol. Inst. Oceanogr. Venezuela. Univ. Oriente. 25 (1-2): 137-154.

Schubert, C. 1972. Geología de la Península de Araya estado Sucre. IV. Congreso Geológico venezolano. Geología General y Estratigrafía. Parte III. Bol. Geol. 5.1823-1886.

Senior, W., G. Martínez, J. Castañeda \& R. Aparicio. 1999. Caracterización de los sedimentos superficiales del sector oriental del Golfo de Cariaco. Bol. Inst. Oceanogr. Venezuela. Univ. Oriente. 38 (1):98-100.

Simpson, J. \& R. GRIFFith. 1967. La distribución de densidad pesquera en el Golfo de Cariaco, Venezuela oriental. Serie: Recursos y explotación pesqueros. 1(8): 305-320.

Stephenson, A., I. Labunska, R. Stringer \& D. Santillo.1998. Identificación y trascendencia ambiental de los contaminantes orgánicos y de los metales pesados hallados en las muestras de agua y sedimentos tomados en la Cuenca Matanzas-Riachuelo, Argentina. Lab. Invest. De Greenpeace, Univ, Exeter, Reino Unido.47 pp.

VALDERRAMA, J. 1981. The simultaneous analysis of total nitrogen and total phosphorus in natural waters. Mar. Chem. 10: 109-122. 
Vignali, M. 1965. Estudio geológico de las rocas sedimentarias de Araya. Geos. UCV. 13:23-26.

Vogel, A. 1960. Química Analítica Cuantitativa. Vol.1. Kapelusz, S.A (Ed). Argentina. 811 pp.

RECIBIDO: Junio 2005

Aceptado: Noviembre 2005
Wells, M. \& L. MaYer. 1991. Variations in the chemical lability of iron in estuarine coastal and shelf waters and its implication for phytoplankton. Mar. Chem. 32: $195-210$. 